\title{
The Effect of the Light Intensity and Light Distances of LED and QTH Curing Devices on the Hardness of Two Light-Cured Nano-Resin Composites
}

\author{
Pnina Segal, Diva Lugassy, Eitan Mijiritsky, Michal Dekel, Ariel Ben-Amar, \\ Zeev Ormianer, Shlomo Matalon \\ Department of Oral Rehabilitation, School of Dental Medicine, Tel Aviv University, Tel-Aviv, Israel \\ Email:matalons@post.tau.ac.il
}

Received 15 September 2015; accepted 24 November 2015; published 27 November 2015

Copyright @ 2015 by authors and Scientific Research Publishing Inc.

This work is licensed under the Creative Commons Attribution International License (CC BY). http://creativecommons.org/licenses/by/4.0/

(c) (i) Open Access

\section{Abstract}

Background: Effective polymerization of the composite resin is essential to obtain long term clinical success and has a great importance obtaining improved mechanical properties. The purpose of this study was to measure the effect of the light intensity of LED and QTH curing devices in relation to the light distances, on the hardness (KHN) of two light cure nano-resin composite. Material and Methods: The top and bottom surfaces of the two nanofill composite specimens were evaluated. Two LED and two QTH light curing devices were used at nine different distances. Light intensity was measured with two radiometers placed at these same distances from the curing tip. 360 pvc dies were prepared with circular cavity $3 \mathrm{~mm}$ in diameter and $2 \mathrm{~mm}$ thick. The tested materials were placed in each cavity. The different light curing distances were standardized by adding pvc spacers dies at different height matching the different distances. Top and bottom surface microhardness were evaluated with a Micro Hardness Tester in knoop hardness numbers $\left(\mathrm{Kg} / \mathrm{mm}^{2}\right)$. Data were statistically analyzed using: Three-way ANOVA, Tukey and Pearsons test. Results: It was revealed that there was a statistically significant difference in microhardness between the composites $(p<0.001)$, between the nine distances $(p<0.001)$ and between the four light curing devices $(p<0.001)$. Increasing the distance of the light source from composite resin, the light intensity and the microhardness values at the top and bottom surface decrease. LED light curing devices produced a greater microhardness results at the bottom surface of the specimens. The Filtek Ultimate nanocomposite $(3 \mathrm{~m})$ showed highest microhardness values on the top and bottom surfaces, polymerized with all four curing devices and all nine distances compared to Empress Direct nano composite (Ivoclar vivadent). Clinical significant: Even with high power LED curing light, the distance between the tip of the light source and the restoration surface should be as close as possible. In this study, Filtek Ultimate showed better results (highest microhardness values) than Empress 


\section{Direct.}

\section{Keywords}

\section{Light-Curing Devices, Nano-Filled Resin Composites, Microhardness}

\section{Introduction}

In the 1970s, a light-activated resin composite was introduced in restorative dentistry. Since then, much effort has been directed toward improving the properties and resistance of resin composite restoration in the oral environment [1] [2]. Light-curing devices and light-activated resin composites have improved remarkably since then [3].

First attempts used an ultraviolet light-activated composite [4] [5] but this material's low polymerization depth [6] [7] and iatrogenic side effects [8], led to its replacement by composites activated by visible light. These latter are currently in use and continue to undergo further development [4] [5] [9].

At present, restorative dentistry uses quartz-tungsten-halogen (QTH), light-emitting diode (LED), plasma arc (PAC), and argon laser light-curing devices [5] [9]-[11]. Among these devices, the QTH and LED lights are the most widely used in dental clinics [10].

QTH devices were introduced in the late 1970s [4]. In these devices, light is produced by an electric current which flows through a tungsten filament inside a bulb full of halogen gas [9] [11]. Blue light with a wavelength of $410-500 \mathrm{~nm}$ is produced using filters [4] [5] [9] [10]. The mean light intensity of these devices is 400 - 800 $\mathrm{mW} / \mathrm{cm}^{2}[5][11]$.

LED devices were first introduced to the field of dentistry in 2000 [4]. In these devices, the electric current passes through the junctions of two doped semi-conductors composed of gallium nitride [4] [9]. These devices emit a narrow spectrum of blue light from 450 to $490 \mathrm{~nm}$, with a peak wavelength of about $468 \mathrm{~nm}$ [12].

The light intensity of second-generation LED light-curing devices has reached $1000 \mathrm{~mW} / \mathrm{cm}^{2}$, and most new LED devices have a light intensity between 1000 and $2000 \mathrm{~mW} / \mathrm{cm}^{2}$ [13].

Light produced by light-curing devices initiates polymerization of the composite resin only when the curing light intensity and wavelength $(470 \mathrm{~nm})$ are sufficient to activate the photoinitiator camphorquinone, which reacts with an amine-reducing agent to form free radicals and polymer chains [14] [15].

Efficient polymerization of the composite resins is essential to the clinical success of the restoration [16]. The quality is affected by many factors, such as the light intensity [15] [17]-[19], duration of exposure time [15] [20] [21], light-curing distance [18] [22]-[27], resin shade [24] [25], thickness of the composite [23], diameter of the light guide in the light-curing device [22], composition of the composite [28], and intactness of light beam [29].

An inverse relationship was found between the light distance and the light intensity absorbed in the layers of composite resin. As the light distance increases, the light intensity decreases; accordingly, the light intensity absorbed by the monomer and the hardness of the composite resin also decreases [18] [27]. The hardness of the composite resin has been examined to evaluate the extent of material polymerization in relation to the lightcuring devices [26]. This was performed by comparing the hardness of the upper surface area (top) to the lower surface area (bottom) [30].

Composites with high durability under occlusion loads usually contain high amounts of filling particles [31]. This may result in surface roughness after polishing and a tendency toward external discoloration [31]-[33]. In order to overcome these disadvantages, micro-filled composites were developed that had excellent polishability but poor physical and mechanical properties [31]-[33]. In an attempt to integrate the advantages of these two types of materials, a hybrid composite was developed with mixtures of particles. This hybrid allows higher filler levels while still permitting good external polishing [31] [33].

More recently, nano-filled resin composites have been introduced with improved physical and mechanical properties [3] [10] [31], high resistance to wear [3] [34] [35], very good polishability [36], and decreased shrinkage during the polymerization process [10]. This new material has a high percentage of filler (over 79.5\%/wt) [10], with particle sizes between 0.005 and $0.01 \mu$ [31].

In the present study, the Knoop hardness of two different nano-filled resin composites were examined using 
two LED and two QTH light-curing devices at various light-curing distances. The light intensity of the curing units was evaluated at each distance by radiometer.

Null Hypothesis:

1) The Knoop hardness of the two different nano-filled resin composites, on the top and on bottom surfaces, will remain consistent in relation to the light-curing distance.

2) The light intensity is consistent based on the distance from the device regardless of which light-curing device is used.

\section{Materials and Methods}

Two resin composites were tested. They are known by their commercial names:

1) Filtek Ultimate Universal Restoration, shade A2 dentin (3M, St. Paul, MN, USA).

2) Empress Direct, shade A2 dentin (Ivoclar Vivadent, Schaan, Liechtenstein). The properties of these materials are provided in Table 1.

Four different light-curing devices were used: two were QTH light-curing devices (Optilux 501/Kerr, Orange, CA, USA; Elipar 2 ESPE/3M ESPE, St. Paul, MN), and two were LED light-curing devices (Elipar S10 LED/ 3M ESPE, St. Paul, MN; Delma pm-LED 04/Delma ${ }^{\circledR}$, Zhejiang, China).

One hundred eighty specimens of each resin composite were prepared. A total of 360 specimens were tested at nine different distances using the four light-curing devices (five specimens for each distance, $n=5$; Figure 1).

The specimens were placed in 360 dies of opaque PVC (polyvinyl chloride) prepared by laser cutting (Rampal Plastics, Netanya) to $18 \times 18 \times 2 \mathrm{~mm}$. In the center of each die, a round hole with $\mathrm{r}=1.5 \mathrm{~mm}$ was prepared for the tested resin.

To determine the light-curing distances, identically sized dies $(18 \times 18 \mathrm{~mm})$ with different thicknesses were prepared that correspond to the different light-curing distances. A round hole with $\mathrm{r}=4 \mathrm{~mm}$ was prepared at the center of each upper die. This die was placed on top of the die with the specimen, and the light-curing tip was placed at a $90^{\circ}$ angle to the surface area (Figure 1).

The distances between the light-curing guide and the specimen were $0,1,2,3,4,5,6,8$, and $10 \mathrm{~mm}$. The composite resin specimens were packed in one increment. A transparent celluloid matrix (Mylar strip) was placed on the top and bottom surfaces of each specimen in order to obtain a smooth surface area and to prevent an inhibition layer from forming, as the inhibition layer would not polymerize well due to the influence of oxygen in the air. Two glass plates were placed over them on a dark surface, and the upper glass was removed before polymerization. All of the specimens underwent polymerization from above for 40 seconds.

The light intensity of the LED and QTH curing devices was measured by radiometer (SDI LED Radiometer/ SDI, Brunsdon, St.Bayswater, Victoria, Australia; Optilux 100/kerr, Orange, CA, USA). To verify that there was no decrease in the light intensity of the device itself, the light intensity was examined again at a distance of

Table 1. The composition of the two composite resins.

\begin{tabular}{|c|c|c|c|c|c|}
\hline Material & Composition & Filler vol (\%) & Filler wt (\%) & $\begin{array}{l}\text { Particles size of the } \\
\text { filler (nanometer) }\end{array}$ & Manufacturer \\
\hline $\begin{array}{c}\text { Filtek Ultimate } \\
\text { Universal } \\
\text { Restorative } \\
\text { Material }\end{array}$ & $\begin{array}{l}\text { Monomer: Bis-GMA, UDMA ,TEGDMA, } \\
\text { PEGDMA and Bis-EMA resins. } \\
\text { Filler: } \\
\text { a non-agglomerated /non-aggregated } 20 \mathrm{~nm} \\
\text { silica filler, a non-agglomerated/ } \\
\text { non-aggregated } 4 \text { to } 11 \mathrm{~nm} \text { zirconia filler and } \\
\text { an aggregated zirconia/silica cluster filler. }\end{array}$ & $63.30 \%$ & $78.50 \%$ & $600-10,000 \mathrm{~nm}$ & 3M ESPE \\
\hline $\begin{array}{l}\text { Empress } \\
\text { Direct }\end{array}$ & $\begin{array}{l}\text { Monomer: } \\
\text { Bis-GMA, UDMA, Tricyclodocandi Metianol } \\
\text { Dimethacrylat } \\
\text { Filler: } \\
\text { barium glass, ytterbium trifluoride, } \\
\text { mixed oxide, silicon dioxide and } \\
\text { copolymer } \\
\text { Additional contents: } \\
\text { additives, catalysts, stabilizers and } \\
\text { pigments }\end{array}$ & $52 \%-59 \%$ & $75 \%-79 \%$ & $550 \mathrm{~nm}$ & Ivoclar Vivaent \\
\hline
\end{tabular}




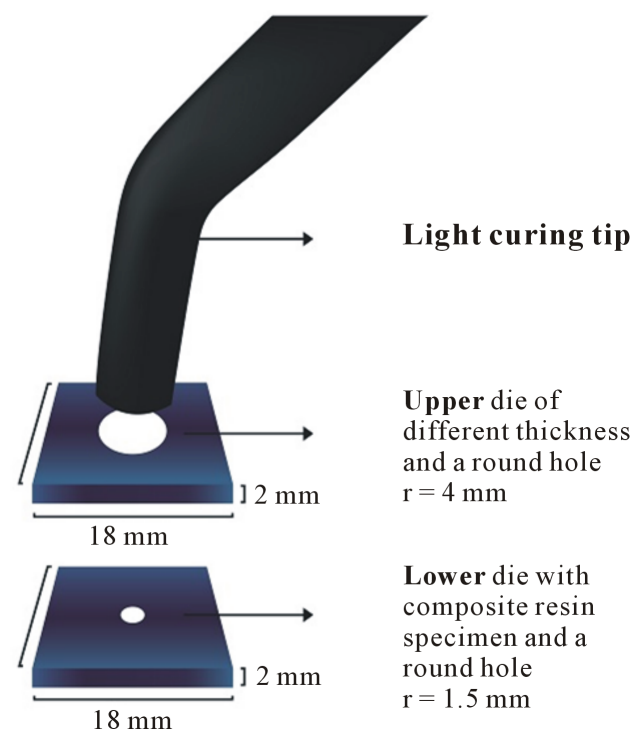

Figure 1. The experimental setup.

$0 \mathrm{~mm}$ before polymerization of the first, third, and fifth dies. After polymerization, the specimens were stored for 24 hours in a humid environment at $37^{\circ} \mathrm{C}$ to allow the dark curing process to complete. After 24 hours, the specimens were polished with a fine polishing Sof-Lex disc (3M ESPE, St. Paul, Minn) connected at low speed (OSADA, Shinagawa-Ku, Tokyo, Japan) without water cooling.

The Knoop hardness of the top and bottom of each specimen was measured by a microhardness tester, model DMH-2 9 (Matsunawa Seikico, Ltd., Tokyo, Japan), using a magnification of 40× at a load of 50 gr. for 12 seconds. Three measurements were performed on each side of every specimen (center and both sides). The mean measurements of all the surface areas were translated into Knoop units of hardness $\left(\mathrm{kg} / \mathrm{mm}^{2}\right)$.

\section{Statistical Processing of Results}

Three-way variance analyses were performed according to the composite resin, distance, and device, using t-tests, one-way ANOVA, and Tukey's post hoc tests.

The Pearson's test was performed to demonstrate the connection between light intensity and the resin composite hardness.

\section{Results}

As the light-curing distances increased, the light intensity decreased accordingly in all four light-curing devices (Table 2). A correlation was found between the light intensity and hardness of the resin composite at the top and the bottom (Pearson's correlation).

The correlation between the hardness of the resin composite on the top and the light intensity was moderate $(\mathrm{R}=0.276)$ and is statistically significant $(\mathrm{P}<0.001)$ for all four light-curing devices. The correlation between the hardness of the resin composite on the bottom and the light intensity was stronger $(R=0.602)$ than the correlation at the top and is statistically significant $(\mathrm{P}<0.01)$ for all four light-curing devices.

The microhardness means (KHN) and standard deviation of the two resin composites at the different lightcuring distances are shown in Table 3 and Table 4.

A three-way variant analysis according to the device, distance, and resin composite was performed on the hardness of the top and bottom of the resin composite as seen in Table 3 and Table 4 . This analysis found the following:

- There was a significant difference in the Knoop hardness between the two resin composites $(\mathrm{P}<0.001)$ and the nine distances $(\mathrm{P}<0.001)$ in all four light-curing devices.

- There was a significant difference among the four light-curing devices $(\mathrm{P}<0.001)$ in the Knoop hardness measurements. 
Table 2. Light intensity mean values in correlation to the light source distance.

\begin{tabular}{ccccc}
\hline \multirow{2}{*}{ Distance (mm) } & \multicolumn{4}{c}{ LIGHT INTENSITY MW/CM $^{2}$} \\
\cline { 2 - 5 } & Elipar 2 ESPE QTH & Optilux 501 QTH & Delma LED & Elipar S10 LED \\
\hline 0 & 576 & 516 & 1328 & 1478 \\
1 & 468 & 408 & 959 & 1062 \\
2 & 434 & 382 & 923 & 925 \\
3 & 402 & 352 & 837 & 836 \\
4 & 376 & 302 & 728 & 731 \\
5 & 346 & 300 & 673 & 645 \\
8 & 318 & 288 & 597 & 581 \\
10 & 280 & 230 & 484 & 494 \\
\hline
\end{tabular}

Table 3. Means of hardness (KHN) on the top and standard deviation of the Filtek Ultimate composite resin at different light-curing distances by the four light-curing devices.

\begin{tabular}{ccccc}
\hline \multirow{2}{*}{ Distances (mm) } & \multicolumn{3}{c}{ Microhardness average (KHN) and standard deviations } \\
\cline { 2 - 5 } & Elipar 2 ESPE QTH & Optilux 501 QTH & Delma LED & Elipar S10 LED \\
\hline 0 & $57.82 \pm 2.81$ & $67.98 \pm 6.62$ & $69.98 \pm 2.68$ & $69.56 \pm 3.56$ \\
1 & $57.74 \pm 2.12$ & $63.72 \pm 4.75$ & $69.70 \pm 1.10$ & $68.42 \pm 8.39$ \\
2 & $57.24 \pm 3.94$ & $63.26 \pm 5.03$ & $66.24 \pm 2.90$ & $66.08 \pm 5.67$ \\
3 & $52.28 \pm 6.47$ & $61.12 \pm 2.95$ & $61.96 \pm 7.19$ & $61.70 \pm 4.56$ \\
4 & $52.32 \pm 6.88$ & $60.24 \pm 3.40$ & $60.64 \pm 6.14$ & $61.54 \pm 2.01$ \\
5 & $50.08 \pm 8.58$ & $58.16 \pm 3.11$ & $60.20 \pm 4.57$ & $59.42 \pm 8.88$ \\
8 & $50.92 \pm 4.15$ & $56.94 \pm 3.75$ & $54.70 \pm 2.93$ & $58.48 \pm 5.31$ \\
10 & $52.24 \pm 4.02$ & $53.02 \pm 8.32$ & $53.06 \pm 5.37$ & $58.50 \pm 3.34$ \\
\hline
\end{tabular}

Table 4. Means of hardness (KHN) on the bottom and standard deviation of the Filtek Ultimate composite resin at different light-curing distances by the four light-curing devices.

\begin{tabular}{|c|c|c|c|c|}
\hline \multirow{2}{*}{ Distance (mm) } & \multicolumn{4}{|c|}{ Microhardness average (KHN) and standard deviations } \\
\hline & Elipar 2 ESPE QTH & Optilux 501 QTH & Delma LED & Elipar S10 LED \\
\hline 0 & $39.28 \pm 3.85$ & $38.90 \pm 3.24$ & $54.98 \pm 5.79$ & $46.22 \pm 3.19$ \\
\hline 1 & $32.68 \pm 3.26$ & $35.02 \pm 3.93$ & $48.24 \pm 11.07$ & $46.20 \pm 5.12$ \\
\hline 2 & $32.20 \pm 5.25$ & $34.38 \pm 8.81$ & $45.96 \pm 6.50$ & $46.76 \pm 6.18$ \\
\hline 3 & $30.88 \pm 3.76$ & $33.18 \pm 6.35$ & $45.64 \pm 8.22$ & $43.26 \pm 11.21$ \\
\hline 4 & $27.22 \pm 2.44$ & $32.92 \pm 5.26$ & $46.36 \pm 4.68$ & $37.32 \pm 3.56$ \\
\hline 5 & $26.60 \pm 3.12$ & $28.18 \pm 4.55$ & $46.58 \pm 3.89$ & $39.48 \pm 4.32$ \\
\hline 6 & $26.82 \pm 5.34$ & $32.78 \pm 2.19$ & $33.6 \pm 2.73$ & $34.04 \pm 7.37$ \\
\hline 8 & $23.54 \pm 5.63$ & $26.60 \pm 6.29$ & $29.72 \pm 1.81$ & $29.76 \pm 3.72$ \\
\hline 10 & $18.10 \pm 4.00$ & $21.10 \pm 4.24$ & $25.48 \pm 5.80$ & $29.48 \pm 5.16$ \\
\hline
\end{tabular}


- The Knoop hardness on the top and the bottom of the specimens is affected by the interaction between the resin composite and the device ( $\mathrm{P}<0.001$, Figure 2, Figure 3 ).

The Knoop hardness measurement on the bottom is affected by the interaction between the resin composite and the distance $(P=0.003$, Figure 4$)$ and by the interaction between the device and the distance $(P<0.001$, Figure 5).

A one-way ANOVA test and Tukey's post hoc test were used to more fully understand how the microhardness measurements vary according to light-curing distance, resin composite, and light-curing device. The test results showed an inverse relationship between the hardness of the resin composite on the top and bottom and

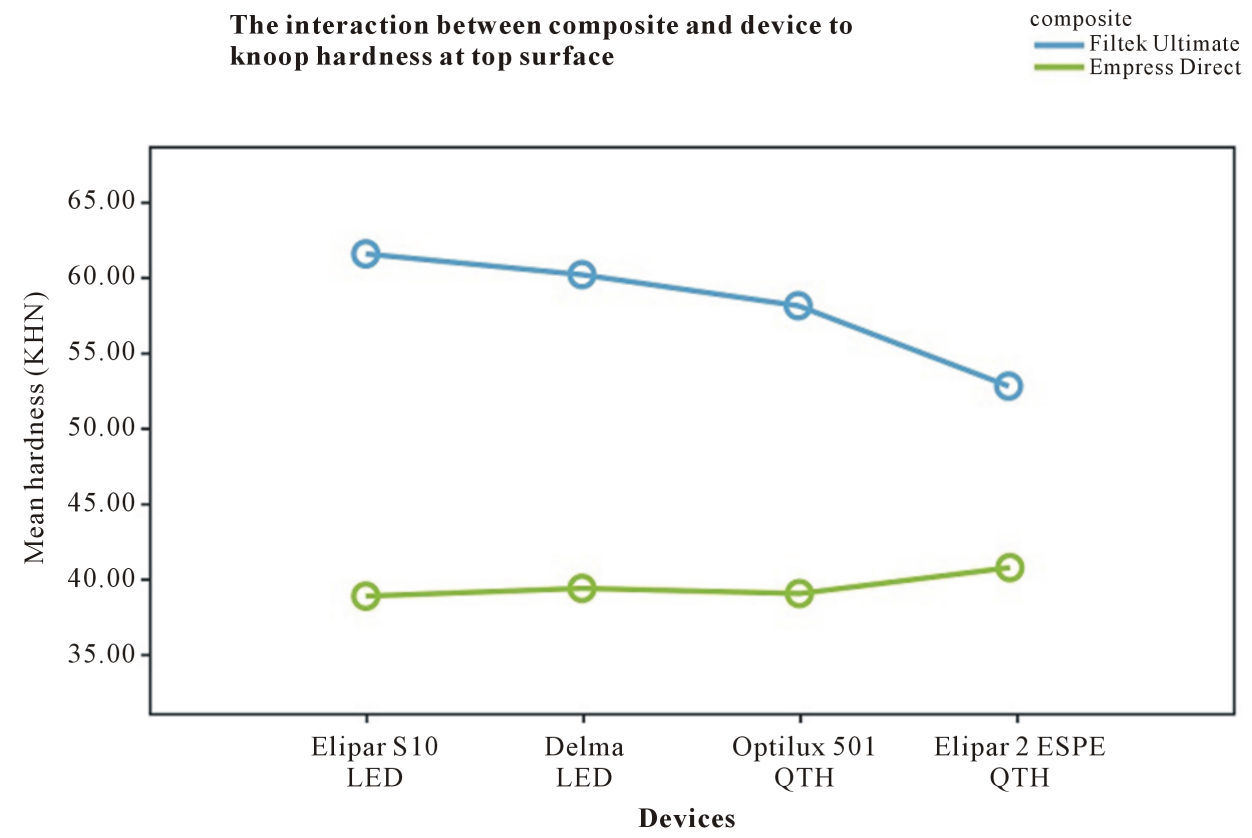

Figure 2. The interaction between the hardness of the top, the devices, and the composite resin.

The interaction between composite and device to

composite

knoop hardness at bottom surface Filtek Ultimate

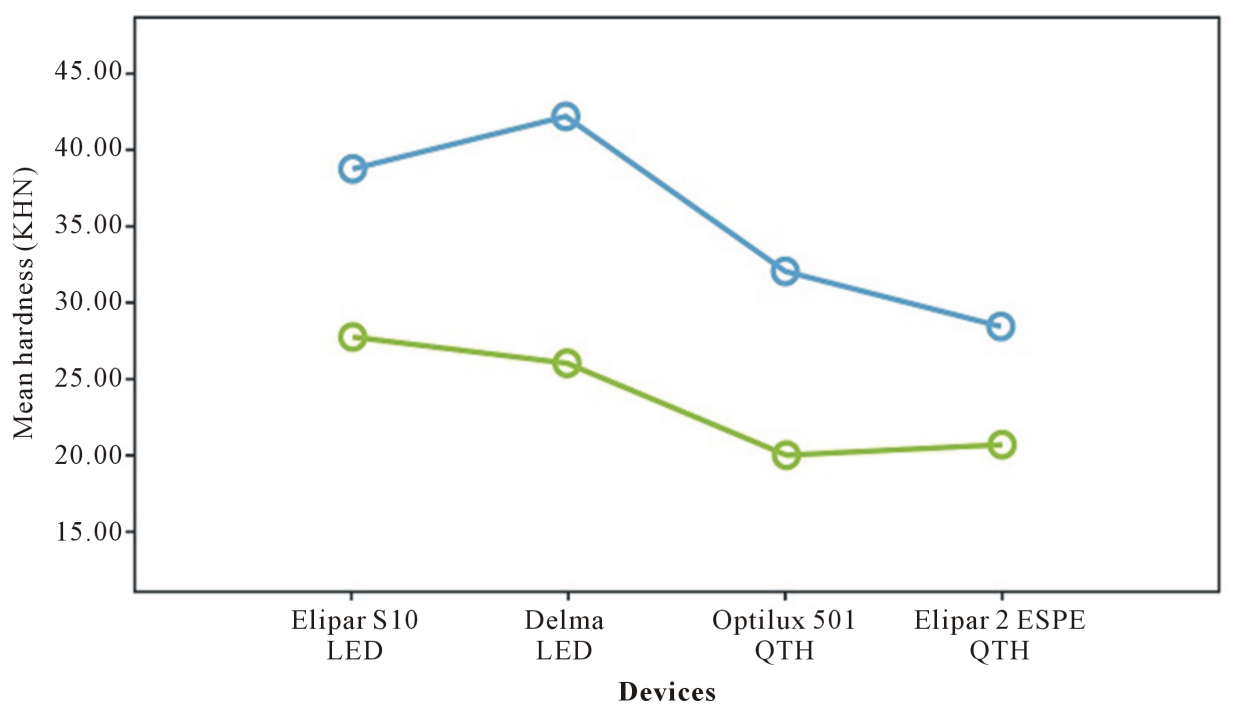

Figure 3. The interaction between the hardness of the bottom, the devices, and the composite resin. 


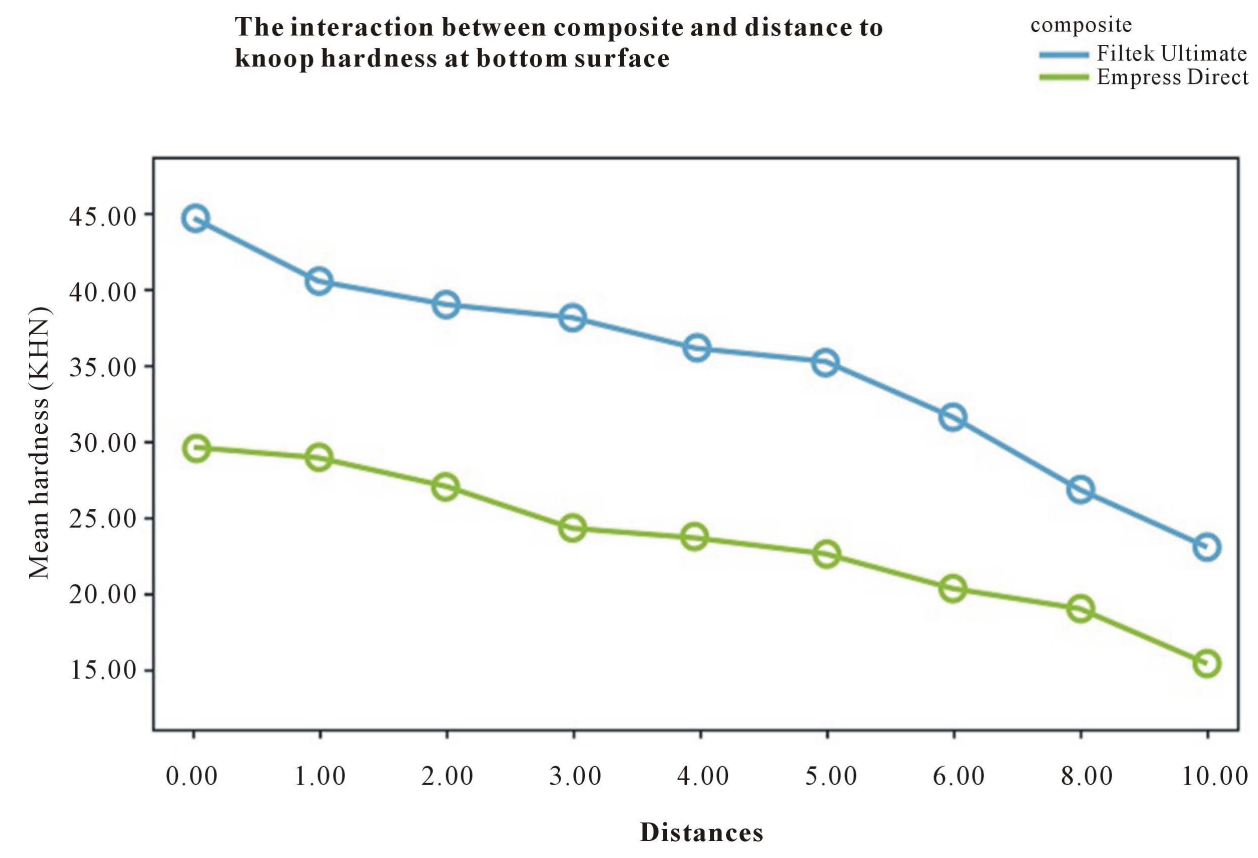

Figure 4. The interaction between the hardness of the bottom, the distance, and the composite resin.

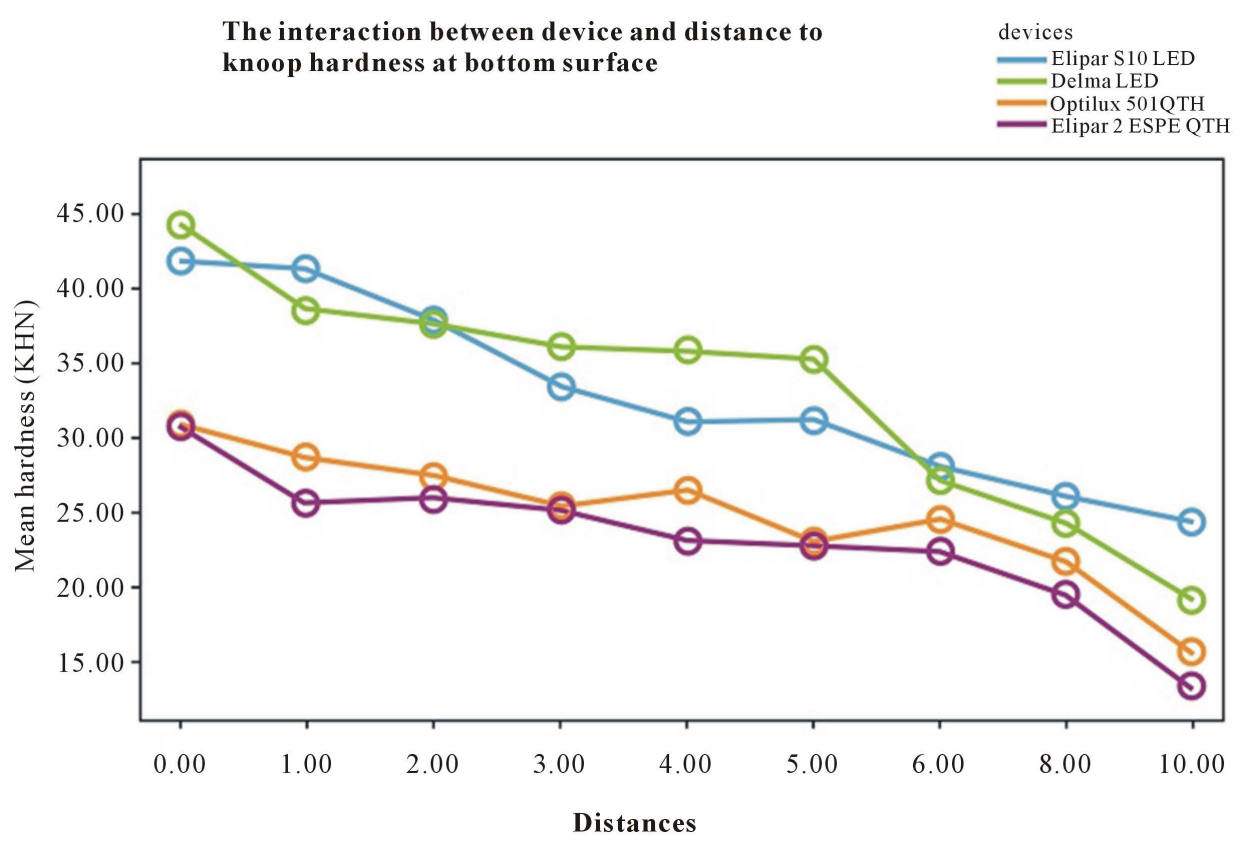

Figure 5. The interaction between the hardness of the bottom, the devices, and the distances.

the different light-curing distances. That is, as the light-curing distance increased, the hardness decreased accordingly (Table 3 and Table 4). All of the results showed statistical significance except for those from the combination of the Filtek Ultimate resin composite with the Elipar 2 ESPE device on the top. In that case, the hardnesses at light-curing distances 3,4 , and $8 \mathrm{~mm}$ were almost identical, which is contrary to what was expected.

In addition, very prominent and statistically significant differences were found between the hardnesses at short distances $(0,1$, and $2 \mathrm{~mm})$ and those at far distances $(6,8$, and $10 \mathrm{~mm})$ on the top and bottom of the two resin composites in polymerization with all four light-curing devices (Table 3 and Table 4). The best results (highest degree of hardness) were always obtained at distances of 0,1 , and $2 \mathrm{~mm}$, and the worst results (lowest 
degree of hardness) were always obtained at 6,8 , and $10 \mathrm{~mm}$. At intermediate distances (3, 4, and $5 \mathrm{~mm}$ ), less prominent differences were observed.

As above, one-way ANOVA and Tukey's post hoc tests were used to examine in greater detail the differences between the four light-curing devices according to the resin composite and light-curing distances. The results showed that a higher degree of hardness was obtained on the bottom when using LED light-curing devices compared with the use of halogen devices (Figure 4).

On the top, higher values of hardness were obtained with LED light-curing devices and the Filtek Ultimate resin composite when compared with QTH devices at light-curing distances of 0, 1, 2, 3, and $4 \mathrm{~mm}$ (with the Empress Direct composite resin, this trend held at 0 and $2 \mathrm{~mm}$ only). However, at light-curing distances of 5, 6, 8, and $10 \mathrm{~mm}$, no statistically significant difference was found between the LED and QTH light-curing devices (3, 4, 5, 6, 8, and $10 \mathrm{~mm}$ with Empress Direct).

Among the LED devices, the Delma resulted in slightly higher hardness values than the Elipar S10. Among the QTH devices, the Elipar 2 ESPE resulted in lower hardness results.

A t-test was performed to examine in greater detail the differences between the resin composites depending on each device and distance. From this test it appeared that polymerization of the Filtek Ultimate resin composite resulted in a significantly better degree of hardness than that of the Empress Direct resin composite, on the top as well as on the bottom, regardless of light-curing device or distance.

\section{Discussion}

The present study examined the influence of four light-curing devices at different distances on the hardness of the top and bottom of two different nano-filled resin composites.

The hardness of the light-cured resin composites depends on several factors: the composition of the organic matrix [37], the type and amount of filler particles [38], and the degree of polymerization [39]. During polymerization, the irradiated light produced by the light-curing devices penetrates the resin and is absorbed by the photoinitiator (camphorquinone, or CQ). Free radicals are formed through the activation of CQ, splitting into $\mathrm{C}=\mathrm{C}$ double bonds of the monomer and forming polymer chains [14]. An examination of the resin composite microhardness (Knoop) was used to evaluate the rate of polymerization [25] [26] [40].

Efficient polymerization is important for obtaining the optimal physical properties of the material and achieving improved clinical performance of resin composite restorations [16] [20]. This study demonstrated that the polymerization process for resin composites is very dependent on the light-curing distance. As expected, an inverse relationship exists between the light-curing distance and the microhardness on the top and bottom of the resin composite. As the light-curing distance increases, the hardness decreases accordingly. Similar results were found in previous studies by Pires et al. [18], Correr et al. [27], and Rode et al. [41]. In addition, there were significant differences in the microhardnesses at shorter light-curing distances (such as at 0,1 , and $2 \mathrm{~mm}$ ) compared with longer distances $(6,8$, and $10 \mathrm{~mm})$. That is, the microhardness measurements at distances of 6 , 8 , and $10 \mathrm{~mm}$ were the lowest for all the devices and for the two materials on the top and bottom (Figure 4 and Figure 5). These results showed that, at a distance longer than $6 \mathrm{~mm}$, there are no significant differences between the light-curing device efficiencies and between the different restorative materials. This means that, at a distance of $6 \mathrm{~mm}$ and beyond, the polymerization rate will not be sufficient regardless of device. This finding is in accordance with the previous study of Caughman et al. [14], which showed that the distance between the light source and the composite's surface should be no greater than $6 \mathrm{~mm}$. Price et al. [30], found that, under clinical conditions in Class I restorations, the minimal distance between the tip of the light-curing device and the resin composite is $2 \mathrm{~mm}$; whereas, in Class II restorations, the distance between cavity surface and the gingival wall may reach $7 \mathrm{~mm}$ and higher. Actually, clinical problems arise with a distance of more than $8 \mathrm{~mm}$ between the lightcuring tip and the bottom of the cavity, such as the accessibility of the tip and the direction of the light into the cavity depth and intervening tooth tissue [25], these factors may limit curing effectiveness. To overcome these problems, various researchers recommend lengthening the exposure time and/or using layering with increments of approximately $1 \mathrm{~mm}$ [25] [41] [42]. There are also very narrow light-curing barrels which can get closer to the cavity floor [43].

The light intensity at a suitable wavelength is important to the polymerization process of resin composites [14]. The light intensity of light-curing devices decreases as the light-curing distance increases, as well as during passage through the layers of resin composite [18] [24] [27].

The decrease in light intensity at various distances, was significantly correlated to the decrease in resin com- 
posite hardness on the top and bottom. We stress that this correlation was more significant on the bottom of the resin composite. The explanation for this is that the light scatters and is reflected and absorbed when passing through the organic matrix and filler particles of the resin composite. As a result, there is a decrease in the intensity of light energy reaching the bottom of the composite resin [24]. The top surfaces are closer to the light-curing barrel; therefore, relatively lower light intensity will also harden them efficiently. This is in contrast to the bottom surfaces that are farther from the light-curing barrel (the thickness of the specimen in this trial is $2 \mathrm{~mm}$ ). Thus, the light intensity has less influence on the hardness of the top surface than the hardness of the bottom surface [24]. Indeed, this study found no significant differences in the hardness of the top surface between QTH and LED devices, despite the higher light intensity of the LED units. However, the hardness on the bottom was always higher after polymerization with LED devices. Therefore, the light intensity of light-curing devices has greater effect/influence on polymerization of the bottom surface.

In the past, dentists have been taught that the intensity of light exiting the tip decreases inversely with the square of the distance from tip to tooth [44]. However, many studies have shown that the light intensity does not follow this law [42] [45]. In fact, if the distance between the light tip and the restoration does not exceed $10 \mathrm{~mm}$, then the light intensity does not decrease as markedly as it would if the inverse square law held [14]. The results of our study also contradict the inverse square law. According to our radiometer measurements, at a distance of 0 to $1 \mathrm{~mm}$ there is a decrease of approximately 30\% in light intensity for all four light-curing devices. At a distance of $1 \mathrm{~mm}$, the light intensity decreases approximately $10 \%$ for every $1 \mathrm{~mm}$ of increased distance (Table 2).

According to the manufacturer's instructions for the Filtek Ultimate (3M) and Empress Direct (Ivoclar vivadent) resin composites, a minimal light intensity of 400 and $500 \mathrm{~mW} / \mathrm{cm}^{2}$, respectively, and a light-curing duration of 20 seconds are required to harden a $2 \mathrm{~mm}$ layer of restoration material. The results of this study contradict these instructions, especially since we used light curing for a period of 40 seconds to polymerize specimens with a thickness of $2 \mathrm{~mm}$. A guideline quoted by Price et al. [30] is that the difference in microhardness between the top and bottom surfaces should not be above $20 \%$. At that condition, the polymerization of the deep layers of the specimen can be considered efficient. In our study, even at light intensities more than $500 \mathrm{~mW} / \mathrm{cm}^{2}$ and at a distance of $0 \mathrm{~mm}$, the difference in hardness between the top and bottom was over 35\% (Table 4). These findings show that, in conditions compatible with the manufacturer's instructions, a lack of polymerization may occur in the deep layers of the resin composite. This phenomenon is worsened when the light-curing device is old. After continued regular use in dental clinics, there is a reduction in the light intensity that may influence the degree of polymerization [19] [46] [47].

LED light-curing devices are becoming increasingly popular in dental practices because of their relatively narrow emission spectrum, higher light intensity, and lower heat generation compared to QTH light-curing devices [48]. Many studies have compared the efficiency of LED light-curing devices with QTH light-curing devices [48]-[51]. In these studies, as in the present work, the efficiency of the light-curing devices was examined based on the hardness of the resin composite. This hardness is an indirect measure of the efficiency of polymerization and is a standard for the mechanical properties of the material [26] [40]. With the introduction of second-generation LED light-curing devices, studies on or after 2004 have shown that, indeed, these bulbs are more efficient than QTH bulbs for polymerizing resin composites that contain a type CQ photoinitiator. An example of this is the Nagas et al. study in 2010 [26]. This study used halogen lamps at an intensity of 1000 $\mathrm{mW} / \mathrm{cm}^{2}$, an LED at an intensity of $1200 \mathrm{~mW} / \mathrm{cm}^{2}$, and five types of resin composite materials. It was found that the LED light-curing devices were more efficient compared to the halogen lamps. The highest degree of hardness was attained using LED light-curing devices. In the present study, the LED light-curing devices had a clear advantage, as their higher light intensity improved the polymerization of the bottom of the resin composite compared with the halogen devices. Despite the slightly higher light intensity of the Elipar S10 device compared to the Delma device, slightly greater hardness on the bottom was achieved when the Delma light-curing device was combined with the Filtek Ultimate composite resin. It can be surmised that a slightly better correlation exists between the wavelength of the Delma device and the type of photoinitiator in the Filtek Ultimate composite resin. The manufacturers do not publicize the type of photoinitiator used and keep it as an industrial secret.

Some research has demonstrated optimization of the resin composite polymerization using an exposure time of 60 seconds and with increments of $1 \mathrm{~mm}$ [14] [45]. Further studies relating the effect of longer exposure time and thinner increments (about $1 \mathrm{~mm}$ ) on the microhardness of resin composite are needed.

In our study, we examined the microhardness (KHN) of two nano-filled resin composites, Filtek Ultimate and Empress Direct. These restorative materials represent a new generation of (nano-filled) composite resins that 
have a filler material sized approximately 0.04 microns [31]. In these composite resins, the percentage of filler that is composed of inorganic particles is higher and reaches $80 \mathrm{wt} \%$. [10]. As a result, resin composites from this group have improved mechanical properties, increasing the ability to achieve better surface polishing [34][36].

Results show that the microhardness of the Filtek Ultimate was higher in all specimens compared to that of the Empress Direct. The organic matrix of Filtek Ultimate is composed mainly of BisEMA, PEGMA, TEGDMA, UDMA, BisGMA, and filler material composed of zirconia/silica particles (63.3\% filler by volume). In contrast, the organic matrix of Empress Direct is composed mainly of tricyclodocandi metianol dimethacrylat, UDMA, BisGMA, and filler material composed of particles of barium glass/ytherbium trifluoride/silicone dioxide (55.5\% filler by volume). It is possible that the explanation for the differences in these materials' microhardness is due to the differences in the composition of their organic matrix and in the type and the volume percentage of filler particles.

The matrix of Filtek Ultimate contains the organic component TEGDMA (tri ethylene glycol diether dimethacrylate). TEGMA is a molecule that is very reactive and hydrophilic and has a low molecular weight; therefore, at high concentrations, it enables a large number of double bonds per unit of weight and more cross bonds, leading to improved polymerization. Also, the addition of this material reduces the viscosity, enabling a higher filling content. In the end, a harder matrix is obtained [52]. In addition, the filler particles of Filtek Ultimate contain zirconia. According to Craig resin composites containing harder filler particles result in higher microhardness [53].

A study by Chung et al. [38] obtained a correlation between the volume percentage of filler and the hardness (KHN). In our study, the Filtek Ultimate has a higher percentage of filler (63.3\%) than the Empress Direct (55.5\%).

As stated in our study, the Filtek Ultimate displayed greater hardness in all nine of the light-curing distances and with all four light-curing devices compared to the Empress Direct. The explanation for this is attributed to the difference in composition of the materials mentioned above.

The results obtained in our trial are similar to and correspond with the results obtained by Mota et al. [54]. This latter study also found large differences in the microhardness of the various resin composites from the nano-filled group. It should also be noted that, in their study, Filtek Supreme (3M) had higher measurements of microhardness relative to 4 Seasons resin composite (Ivoclar Vivadent).

\section{Conclusions}

We conclude the following from the results of the present study:

1) A correlation exists between the light intensity, as measured by radiometer at different distances, and the hardness of the top and bottom of the composite resin. As the light-curing distance increases, the light intensity and hardness decrease accordingly.

2) For efficient polymerization of the composite resin, the tip of the light-curing device should be at a distance at least $2 \mathrm{~mm}$ from the resin area and no farther than $6 \mathrm{~mm}$.

3) LED light-curing devices have a higher light intensity and are more efficient at polymerizing the bottom of the composite resin compared to halogen bulbs.

4) In contrast, no advantage was observed using the LED bulb to polymerize the top surface of the composite resin.

5) Within the same group of nano-filled resin composites, the degree of hardness may vary between several materials related to differences in their compositions.

\section{Clinical Significance}

In order to obtain efficient polymerization of all the resin composite layers and achieve the best physical properties, clinicians in their daily clinical work should polymerize the resin composite from as short a distance as possible.

\section{References}

[1] Mosner, N. and Salz, U. (2001) New Developments of Polymeric Dental Composites. Progress in Polymer Science, 26, 535-576. http://dx.doi.org/10.1016/S0079-6700(01)00005-3 
[2] Bowen, R.L. and Washington, D.C. (1963) Properties of a Silica-Reinforced Polymer for Dental Restorations. The Journal of the American Dental Association, 66, 57-64. http://dx.doi.org/10.14219/jada.archive.1963.0010

[3] Cramer, N.B., Stansbury, J.W. and Bowman, C.N. (2011) Recent Advances and Developments in Composite Dental Restorative Materials. Journal of Dental Research, 90, 402-416. http://dx.doi.org/10.1177/0022034510381263

[4] Rueggeberg, F.A. (2011) State of the Art: Dental Photocuring-A Review. Dental Materials, 27, 39-52. http://dx.doi.org/10.1016/j.dental.2010.10.021

[5] Malhotra, N. and Mala, K. (2011) Light Curing Considerations for Resin Based Composite Materials: A review. Part 1. Compendium, 31, 498-506.

[6] Ruyter, I.E. and Oysaed, H. (1982) Conversion in Different Depths of Ultraviolet and Visible Light Activated Composite Materials. Acta Odontologica Scandinavica, 40, 179-192. http://dx.doi.org/10.3109/00016358209012726

[7] Wayne, D.C. (1980) Factors Affecting the Depth of Cure of UV-Polymerized Composites. Journal of Dental Research, 59, 800-808. http://dx.doi.org/10.1177/00220345800590050901

[8] Lippke, J.A., Gordon, L.K., Brash, D.E. and Haseltine, W.A. (1981) Distribution of UV Light-Induced Damage in a Defined Sequence of Human DNA: Detection of Alkaline Sensitive Lesion at Pyrimidine Nucleoside-Cytidine Sequences. Proceedings of the National Academy of Sciences, 78, 3388-3392. http://dx.doi.org/10.1073/pnas.78.6.3388

[9] Dental Product Spotlight (2002) Visible Light Curing. Journal of the American Dental Association, 133, $1430-1431$.

[10] Garcia, A.H., Lozano, M.A., Vila, J.C., Escribano, A.B. and Galve, P.F. (2006) Composite Resins. A Review of the Materials and Clinical Indications. Medicina Oral Patologia Oral y Cirugia Bucal, 11, 215-220.

[11] Roberson, T. (2006) Art and Science of Operative Dentistry. 5th Edition, Mosby, St. Louis, 205-210.

[12] Correr, A.B., Coehlho Sinhoreti, M.A., Sobrinho, L.C., Tango, R.N., Jochims, L.F. and Consani, S. (2005) Effect of the Increase of Energy Dentistry on Knoop Hardness of Dental Composites Light-Cured by Conventional QTH, LED and Xenon Plasma Arc. Brazilian Dental Journal, 16, 218-224. http://dx.doi.org/10.1590/S0103-64402005000300009

[13] Kramer, N., Lohbauer, U., Godoy, F.G. and Frankenberger, R. (2008) Light Curing of Resin-Based Composites in the LED Era. American Journal of Dentistry, 21, 135-142.

[14] Caughman, W.F., Rueggeberg, F.A. and Curtis, J.W. (1995) Clinical Guidelines for Photocuring Restorative Resins. The Journal of the American Dental Association, 126, 1280-1282. http://dx.doi.org/10.14219/jada.archive.1995.0364

[15] Chang, J.B., Seok-Hee, H., Sang, K.L., Hyo-Joung, S., Hyung, K. and Yong Hoom, K. (2008) The Effect of Light Intensity and Light-Curing Time on the Degree of Polymerization of Dental Composite Resins. Dental Materials Journal, 27, 523-533. http://dx.doi.org/10.4012/dmj.27.523

[16] Yoon, T.H., Lee, Y.K., Lim, B.S. and Kim, C.W. (2002) Degree of Polymerization of Resin Composite by Different Light Source. Journal of Oral Rehabilitation, 29, 1165-1173. http://dx.doi.org/10.1046/j.1365-2842.2002.00970.x

[17] Mills, R.W., Jandt, K.D. and Ashworth, S.H. (1993) Dental Composite Depth of Cure with Halogen and Blue Light Emitting Diode Technology. British Dental Journal, 186, 388-391.

[18] Pires, J.A.F., Cvitko, E., Denehy, G.E. and Swift, E.J. (1993) Effects of Curing Tip Distance on Light Intensity and Composite Resin Microhardness. Quintessence International, 24, 517-521.

[19] Pilo, A., Oelgisser, D. and Cardash, H.S. (1999) Survey of Output Intensity and Potential for Depth of Cure among Light-Curing Units in Clinical Use. Journal of Dentistry, 27, 235-241. http://dx.doi.org/10.1016/S0300-5712(98)00052-9

[20] Ceballos, L., Fuentes, M.V., Tafalla, H., Martinez, A., Flores, J. and Rodriguez, J. (2009) Curing Effectiveness of Resin Composites at Different Exposure Times Using LED and Halogen Units. Medicina Oral Patologia Oral y Cirugia Bucal, 14, E51-E56.

[21] Leonard, D.L., Charlton, D.G., Roberts, H.W. and Cohen, M.E. (2002) Polymerization Efficiency of Led Curing Lights. Journal of Esthetic and Restorative Dentistry, 14, 286-295. http://dx.doi.org/10.1111/j.1708-8240.2002.tb00524.x

[22] Corciolani, G., Vichi, A., Davidson, C.L. and Ferrari, M. (2008) The Influence of Tip Geometry and Distance on Light Curing Efficacy. Operative Dentistry, 33, 325-331. http://dx.doi.org/10.2341/07-94

[23] Rode, K.M., Kawano, Y. and Turbino, M.L. (2007) Evaluation of Curing Light Distance on Resin Composite Microhardness and Polymerization. Operative Dentistry, 32, 571-578. http://dx.doi.org/10.2341/06-163

[24] Aguiar, F.H.B., Lazzari, C.R., Lime, D.A.N.L., Ambrosano, G.M.B. and Lovadino, J.R. (2005) Effect of Light Curing Tip Distance and Resin Shade on Microhardness of a Hybrid Resin Composite. Brazilian Oral Research, 19, 302-306. http://dx.doi.org/10.1590/S1806-83242005000400012

[25] Thome, T., Steagall Jr., W., Arlene, T., Braga, S.R.M. and Turbino, M.L. (2007) Influence of the Distance of the Curing Light Source and Composite Shade on Hardness of Two Composites. Journal of Applied Oral Science, 15, 486-492. http://dx.doi.org/10.1590/S1678-77572007000600006 
[26] Nagas, I.C., Egilmez, F. and Ergun, G. (2010) The Effect of Irradiation Distance on Microhardness of Resin Composites Cured with Different Light Curing Units. European Journal of Dentistry, 4, 440-446.

[27] Correr, L., Lima, A.A., Consani, S., Coelho Sinhoreti, M.A. and Knowles, J.A. (2000) Influence of Curing Tip Distance on Composite Knoop Hardness Values. Brazilian Dental Journal, 11, 11-17.

[28] Li, Y., Swartz, M.L., Philips, R.W., Moore, B.K. and Roberts, T.A. (1985) Effect of Filler Content and Size on Properties of Composites. Journal of Dental Research, 64, 1396-1401. http://dx.doi.org/10.1177/00220345850640121501

[29] Rueggeberg, F.A., Caughman, W.F. and Comer, R.W. (1996) The Effect of Autoclaving on Energy Transmission through Light-Curing Tips. The Journal of the American Dental Association, 127, 1183-1187. http://dx.doi.org/10.14219/jada.archive.1996.0409

[30] Price, B.T.R., Corey, A.F. and Pantelis, A. (2003) Evaluation of a Second-Generation LED Curing Light. Journal of the Canadian Dental Association, 69, 666a-666h.

[31] Roberson, T. (2006) Art and Science of Operative Dentistry. 5th Edition, Mosby, St. Louis, 500-502.

[32] Ferracane, J.L. (1995) Current Trends in Dental Composites. Critical Reviews in Oral Biology \& Medicine, 6, $302-318$. http://dx.doi.org/10.1177/10454411950060040301

[33] Dijken, J.W.V. (1986) A Clinical Evaluation of Anterior Conventional, Microfiller, and Hybrid Composite Resin Fillings. Acta Odontologica Scandinavica, 44, 357-367. http://dx.doi.org/10.3109/00016358609094346

[34] Yap, A., Tan, C.H. and Chung, S.M. (2004) Wear Behavior of New Composite Restoratives. Operative Dentistry, 29, 269-274.

[35] Topcu, F.T., Erdemer, U., Sahinkesen, G., Yildiz, E., Uslan, I. and Acikel, C. (2010) Evaluation of Microhardness, Surface Roughness and Wear Behavior of Different Types of Resin Composites Polymerized with Two Different Light Sources. Journal of Biomedical Materials Research, 92, 470-478.

[36] Mitra, S.B., Wu, D. and Holmes, B.N. (2003) An Application of Nanotechnology in Advanced Dental Materials. The Journal of the American Dental Association, 134, 1382-1390. http://dx.doi.org/10.14219/jada.archive.2003.0054

[37] Asmussen, E. (1982) Restorative Resins: Hardness and Strength vs. Quantity of Remaining Double Bonds. European Journal of Oral Sciences, 90, 484-489. http://dx.doi.org/10.1111/j.1600-0722.1982.tb00766.x

[38] Chung, K.H. and Greener, E.H. (1990) Correlation between Degree of Conversion, Filler Concentration and Mechanical Properties of Posterior Composite Resins. Journal of Oral Rehabilitation, 17, 487-494. http://dx.doi.org/10.1111/j.1365-2842.1990.tb01419.x

[39] Ferracane, J.L. (1985) Correlation between Hardness and Degree of Conversion during the Setting Reaction of Unfilled Dental Restorative Resins. Dental Materials, 1, 11-14. http://dx.doi.org/10.1016/S0109-5641(85)80058-0

[40] Wang, L., Dalpino, P.H.P., Lopes, L.G. and Pereira, J.C. (2003) Mechanical Properties of Dental Restorative Materials Relative Contribution of Laboratory Tests. Journal of Applied Oral Science, 11, 162-167. http://dx.doi.org/10.1590/S1678-77572003000300002

[41] Rode, K.M., Kawano, Y. and Turbino, M.L. (2007) Evaluation of Curing Light Distance on Resin Composite Microhardness and Polymerization. Operative Dentistry, 32, 571-578. http://dx.doi.org/10.2341/06-163

[42] Hansen, E.K. and Asmussen, E. (1997) Visible Light Curing Units: Correlation between Depth of Cure and Distance between Exit Window and Resin Surface. Acta Odontologia, 55, 162-166. http://dx.doi.org/10.3109/00016359709115410

[43] Malhotra, N. and Mala, K. (2010) Light-Curing Considerations for Resin-Based Composite Materials: A Review Part 2. Compendium, 31, 584-592.

[44] Phillips, R.W. (1982) Skinner’s Science of Dental Materials. 8th Edition, Saunders, Philadelphia, 230.

[45] Cook, W.D. (1986) Curing Efficiency and Ocular Hazards of Dental Photopolymerization Sources. Biomaterials, 7, 449-454. http://dx.doi.org/10.1016/0142-9612(86)90033-5

[46] Barghi, N., Berry, T. and Hatton, C. (1994) Evaluating Intensity Output of Curing Lights in Private Dental Offices. The Journal of the American Dental Association, 125, 992-996. http://dx.doi.org/10.14219/jada.archive.1994.0204

[47] Ashaafi, M.M., Maawadh, A.M. and Qahtani, M.Q. (2011) Evaluation of Light Intensity Output of QTH and LED Curing Devices in Various Governmental Health Institutions. Operative Dentistry, 36, 356-361. http://dx.doi.org/10.2341/10-247-O

[48] Mousavinasab, S.M. and Meyers, L. (2011) Comparison of Depth of Cure, Hardness and Heat Generation of LED and High Intensity QTH Light Sources. European Journal of Dentistry, 5, 299-304.

[49] Yoon, T.H., Lee, Y.K., Lim, B.S. and Kim, C.W. (2002) Degree of Polymerization of Resin Composites by Different light Sources. Journal of Oral Rehabilitation, 29, 1165-1173. http://dx.doi.org/10.1046/j.1365-2842.2002.00970.x

[50] Uhl, A., Sigusch, B.W. and Jandt, K.D. (2004) Second Generation LEDs for the Polymerization of Oral Biomaterials. 
Dental Materials, 20, 80-87. http://dx.doi.org/10.1016/S0109-5641(03)00095-2

[51] Price, R.B.T., Corey, A.F. and Andreou, P. (2005) Knop Hardness of Ten Resin Composites Irradiated with HighPower LED and Quartz-Tungsten-Halogen Lights. Biomaterials, 26, 2631-2641. http://dx.doi.org/10.1016/j.biomaterials.2004.06.050

[52] Mota, E.G., Weiss, A., Sphor, A.M., Oshima, H.M.S. and Carvalho, L.M.N. (2011) Relationship between Filler Content and Selected Mechanical Properties of Six Microhybrid Composites. Revista Odonto Ciência, 26, 151-155. http://dx.doi.org/10.1590/S1980-65232011000200010

[53] Craig, R.G. (2006) Restorative Dental Materials. 12th Edition, Mosby, St Louis, 190-209.

[54] Mota, E.G., Oshima, H.M.S., Burnett, L.H., Pires, L.A.G. and Rosa, R.S. (2006) Evaluation of Diametral Tensile Strength and Knoop Microhardness of Five Nanofilled Composites in Dentin and Enamel Shades. Stomatologija, 8, 67 69. 